\title{
Drawings We Have Lived: Mapping Desire Lines in Edmonton
}

Erika Luckert

\begin{abstract}
Desire Lines are grassy pathways formed when many people walk the same way over and over again - exploring or shortcutting through city space. Thus, they display an urban history while shaping a space's present as well. From May to August 2012, I mapped and documented Desire Lines in Edmonton. This paper chronicles my methods and findings, and situates the concept of Desire Lines in a larger theoretical context.
\end{abstract}

\section{INTRODUCTION: "imagination has both shaped and been shaped by the spaces it passes through on two feet. Walking has created paths... generated maps"1}

Desire lines are unsanctioned paths worn only by frequent footsteps. They can be seen cutting across grassy fields on a diagonal, or lining the side of the street where there's no sidewalk. Sometimes, desire lines are a means of expediency - they cut corners and find the shortest distance between two points. Other times, they are a means of deviancy and exploration - they chart new territory, and open up paths to places that would otherwise be passed by. In all instances, desire lines are signs of a consensus that their way is worth walking; they are maintained only by the constant use of countless footsteps - without that, the lines fade and are forgotten.

When they do not fade, or until they fade, desire lines serve not only as paths, but also as historical records - making past patterns of footsteps apparent, and allowing the past to directly inform the present as we travel in those footsteps again and again. Michel de Certeau said that "the act of walking is to the urban system what the speech act is to language,"2 and Gaston Bachelard spoke of paths as drawings. A professor of mine, Don Perkins, thought of desire paths as a way that city-dwellers can "write back", to the city-planners, giving feedback with their feet. Paths as histories, as speech, as drawings, and as writings. But how can we read them?

Whether desire lines are the relics of walking, the drawings of a city, or a citizen response to urban planning, they remain a geographical feature - something that might be recorded on a map. A map is something that we know how to read. The challenge, then, becomes the writing of such a map - a record of desire lines that displays them without undermining their nature, without sanctioning the unsanctioned path. What is needed is a map not for

\footnotetext{
${ }^{1}$ Rebecca Solnit, Wanderlust: A History of Walking (New York: Viking, 2000), 4.

${ }^{2}$ Michel De Certeau, quoted in Dieter Roelstraete, Richard Long: A Line Made by Walking (London: Afterall, 2010), 13.

${ }^{3}$ Don Perkins, posting to Theories of Space: Mapping Desire Lines in Edmonton "Project Description," http://desirelines.edmontonpipelines.org/project-description/
} 
navigation, but for exploration. The sort of map that provokes wanderings, and inspires new desire lines. Something that digs deep into the trodden paths, and shows more than just a line on the surface, revealing instead a whole history of movement through urban space. In order to create such a map, I needed to become a wanderer myself; I needed to walk and write the lines so that they could be read.

\section{METHODOLOGY: "knowing the city by pacing off its streets and neighbourhoods, recovering the deep, enduring traces of our inhabitation" 4}

My research on desire lines builds upon the work of a larger research collaborative, the Edmonton Pipelines Project (edmontonpipelines.org). The group is based out of the University of Alberta, and aims to develop urban narratives through creative multimedia mapping. The project uses the site-appropriate metaphor of "pipelines" (Edmonton is an oil city) to suggest ways of channeling understanding through dense city space. Desire Lines is one "pipeline" (subproject) within the larger network of the Edmonton Pipelines Project, and shares with that larger network a desire to explore the quotidian aspects of a city in ways that reveal narrative interest within our navigation of urban spaces.

In order to narrate desire lines in a cartographical form, I employed a number of methods. I walked each path that I encountered, and observed other traffic along the routes. As I walked, I took photographs and video footage, which I then coupled with short creative nonfiction pieces to build a multimedia narrative for each line. These narratives are presented in conjunction with the geographically marked paths on a digital map of my study site.

My study of desire lines in Edmonton was carried out over a survey area east of 105 Street and south of Jasper Avenue, continuing all the way to the river in both directions - an area of about one square kilometer, or 250 acres (see Figure 1). The site is in central Edmonton, with its northern limit running along the main street downtown (Jasper Avenue). It continues south to a quieter, residential area (the Rossdale neighbourhood) that also includes a baseball stadium, a school, and one of the city's water treatment plants, along the North Saskatchewan River. Also along the river is a significant stretch of park space, part of Edmonton's larger river valley parks system. In its entirety, my study area provides a varied sample of urban landscape within a manageable survey space.

\footnotetext{
${ }^{4}$ Shawn Micallef, Stroll: Psychogeographic Walking Tours of Toronto (Toronto: Eye Weekly, 2011), 8.
} 


\section{Figure 1: Study Site}

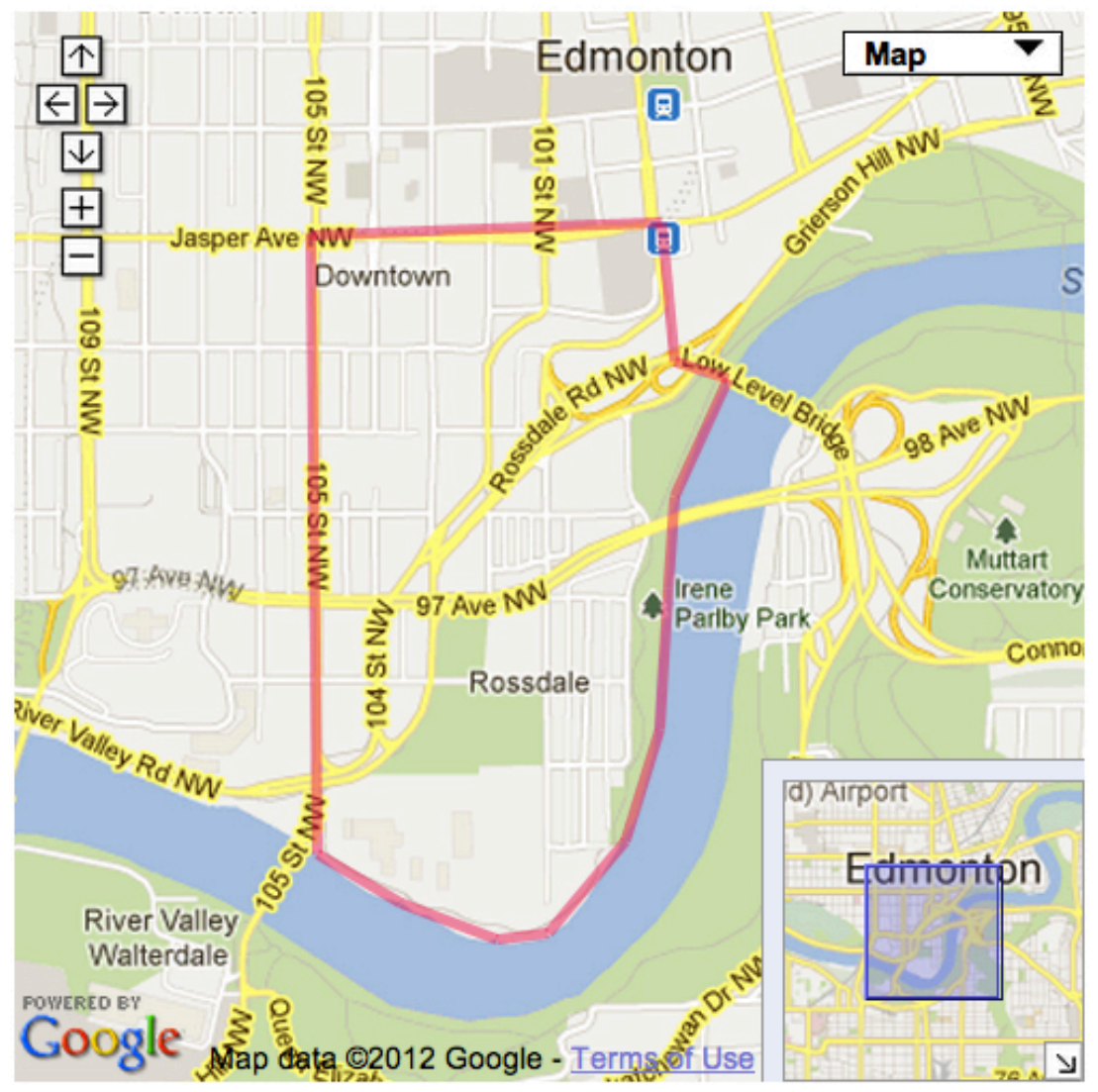

Source: Author illustration.

While my original intention was to use GPS breadcrumb trails to chart the desire lines, I quickly discovered that the method would not be successful. The margin of error in GPS geolocation, usually within a few meters, left desire lines in the middle of a four-lane road instead of cutting from the sidewalk to someone's front door. While the accuracy of a GPS is more than sufficient for driving, or even walking along sanctioned paths, the more subtle line of a desire path winding through a grove of trees turns into a zigzagging mess as a GPS tries to make sense of the route. Clearly, using a "geographically accurate" location method was not accurate enough. Or maybe it was too accurate. My struggles with geolocation forced me to take a step back and think about my objectives in mapping the paths.

While they are physical, geolocatable objects, desire lines seem to have an aspect in their nature that resists such classification. They take imprecise, wandering lines, and, I suspect, the path of those lines change over time. My goal in mapping them is not to provide the sort of map you might use to plan a route between two points. That would defeat the desire line entirely - to map it in that way would be to sanction an unsanctioned path and, ultimately, to 
make it undesirable. But there is something about seeing the shapes and contours of the desire lines that is appealing. I wanted to see where they ran straighter, and where they wound in a more playful manner. The photographs and video that are integrated into the map provide some of that. But in order for the visual whole of the map to display the nature of desire lines over a larger landscape, and to reveal a larger urban history, I needed to trace the paths in some way. In the end, I took my cue from Gaston Bachelard's beautiful words on paths: "thus we cover the universe with drawings we have lived." I decided to draw the paths freehand, in the same organic manner that the paths themselves are created. I used a tool called Scribble Maps (www.scribblemaps.com), which allows freeform annotation over a Google Maps base layer. This tool let me locate the lines with reasonable accuracy over the satellite imagery - ensuring, at least, that no desire lines ran illogically down the middle of a road.

\section{WALKING: "the sense of place that can only be gained on foot" 6}

I think of walking as the primary means that desire lines are formed, and so I have done the bulk of my documentation of the paths on foot. But certainly, there are other modes of formation as well - some desire lines are so thin that they could only be made by a bicycle, and I've seen others that clearly began with the track of a car driving on a grassy area, and only later were adopted by people on foot (see Figure 2). Still, I have considered the act of walking to be a fundamental part of the formation and discourse of desire lines. Of all the desire lines I have observed in my research, it is the walker that I see most often on the paths. If you were to think of the formation of desire lines as an act of writing (an idea to which I'll later return), then our feet must be the pen. Sure, some words are written with pencil or marker or crayon or chalk, but the pen still seems to characterize the form. Likewise, walking seems inextricably linked to desire lines. Our feet hold a most intimate relationship with paths; they come to know them often better than our minds. Thus, desire lines hold a history that is, in many ways, more corporeal than intellectual.

\footnotetext{
${ }^{5}$ Gaston Bachelard and M. Jolas, The Poetics of Space (Boston: Beacon, 1994), 12.

${ }^{6}$ Solnit, Wanderlust, 9.
} 
Figure 2: A Desire Line begun by a car

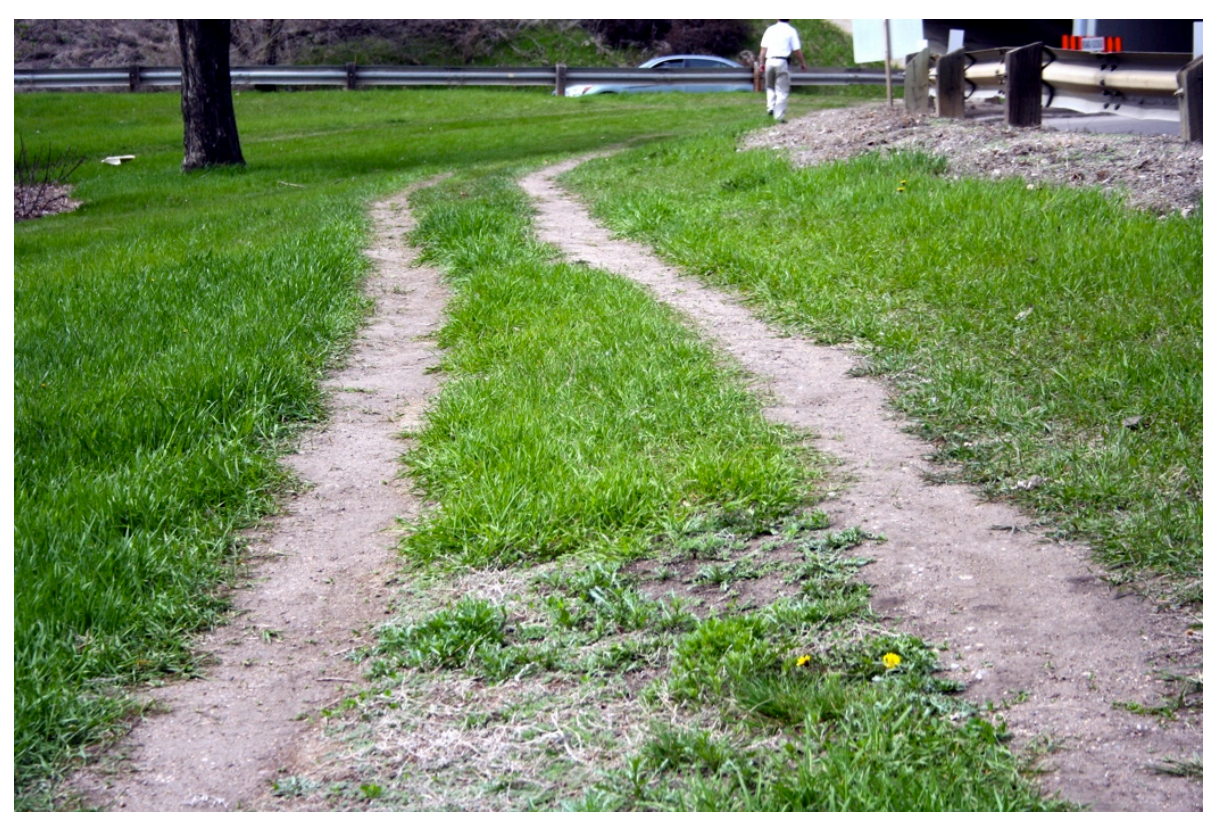

Source: Author photo.

If walking is the primary medium of desire lines, then an understanding of the path must be contingent on an understanding of the walking of it. I made a point of walking every desire line that I encountered in my study, even if I could clearly see to the path's end. An old cliché comes to mind - it's the journey, not the destination. But there's something more to it than that. Rebecca Solnit talks about "the sense of place that can only be gained on foot,", acknowledging the depth of understanding that comes with a slower pace and a corporeal connection to a space. She says that "cities move at the speed of walking,", and while such a claim seems out of place in a modern, suburban city where the bulk of transit is accomplished by car, I do believe that you see a different city when you move through it on foot.

Whether cities move at the speed of a pedestrian or a bus or a car, the pedestrian does have one clear advantage. While the bus and the car must remain on designated roads and alleys, the pedestrian has the entire city literally at their feet. Sure, there are areas that are less accessible on foot - complexes of big box stores like my city's South Edmonton Common

\footnotetext{
${ }^{7}$ Ibid.

${ }^{8}$ Rebecca Solnit, Wanderlust, quoted in Shawn Micaleff, Stroll, 11.
} 
come to mind - 320 acres of retail giants joined by a maze of parking lots and unsigned roads with hardly a sidewalk in sight. ${ }^{9}$ But a more adventurous pedestrian can still navigate in such places. There are limits to how exploratory a driver can be - cars remain confined by the lines of the city's roadways. But a pedestrian is limited only by their own desires - if the line does not exist, they can create it.

\section{ART: "walking is a mode of making the world as well as being in it" 10}

In 1967, someone had "the outrageous (and outrageously simple) idea that walking could be art, and that a line made by walking could be artwork."11 That someone was artist Richard Long, and his artwork was titled "A Line Made by Walking." While Long never used the term "desire line" in his description of the work, that is essentially what it is. In the countryside just outside of London, Long walked back and forth repeatedly until a line was formed, and then took a simple black and white photograph.

There is one primary difference between this work and most desire lines, however. "A Line Made By Walking" was made by one man. Desire Lines, unlike Long's work, are collectively created. Rather than acting as autobiography, they are a social history, something that belongs to a larger population in the rare moments when that population converges. Thus, desire lines have a less deliberate feel to them, more a sense of the coincidental - the coincidence of hundreds of footsteps choosing the same path.

There seems to be an artistry to that coincidence, and for that reason, I find myself continually drawn back to what Gaston Bachelard said of paths, and travelling on them: "thus we cover the universe with drawings we have lived." Desire Lines, then, might be seen as a city's life-drawings, as its most natural form of art, like murals on the ground. Like Long's "A Line Made By Walking," desire lines might be compared to landscape art - not landscape paintings, but the type of works that are built into the landscape itself, created from the landscape (sculptor Robert Smithson's Spiral Jetty is one prominent example). In fact, Long studied sculpture in art school, not photography. In this vein, Roelstraete asks a provocative question:

Is (was) the art in the walking, in the line made by walking, or in the photograph made of the line made by walking? Did the work exist for no longer than the twenty minutes it took to make the narrow strip of flattened grass appear, or does the work continue to exist in its ongoing transportation? ${ }^{12}$

It's a question that I might ask of my own work too. Shall I focus on the composition of my photographs, the arc of my sentences? Or are they really just documentation of an art that is already there, sculpted on the ground? Do these lines exist as elements of a history, or as parts of the present? Can I do justice simply by recording the artful paths, or does the real art come in the formation of the lines themselves - must I witness walkers on the paths, and be a walker on the path myself to truly understand?

\footnotetext{
9 Southedmontoncommon.com, http://www.southedmontoncommon.com/about/

${ }^{10}$ Solnit, Wanderlust, 29.

${ }^{11}$ Dieter Roelstraete, Richard Long: A Line Made by Walking (London: Afterall, 2010), 5.

12 Roelstraete, Richard Long, 3.
} 
If desire lines can be seen as visual art, then they might also be interpreted as words, as dialogues written over city space - messages from pedestrians to a city that doesn't facilitate their desired paths. In some cases, city planners allow desire lines to dictate their constructions: "landscape architects are increasingly embracing desire lines from the outset, allowing desire lines to emerge... and then paving the lines to make permanent walkways.",13 Sometimes, even when this is not a deliberate design strategy, a similar process takes place out of necessity. My professor Don Perkins told such a story of the University of British Columbia campus:

[the campus had to] surrender to popular "voting with their feet" patterns, especially around the Student Union Building. Students (of which I was one at the time) avoided the indirect but orderly right-angled sidewalks and took the direct routes across the lawns. Given the rain, these routes became pretty soggy ruts in no time, and left a lot of students with very wet shoes. Last time I was there, there were concrete walkways on the more direct routes. ${ }^{14}$

Such a result may be seen as a citizen's victory - a triumph of the walkers over the planners. Certainly, the result is desirable on a practical level: people can take their preferred routes without risking muddy shoes on wetter days. But what does it do to desire lines seen as objects of art? Does the paving over of desire lines defeat them, and destroy their artistry? Is it, in a way, akin to painting over an already finished canvas? Would we appreciate Long's "A Line Made By Walking" if it were, instead, "A Line Made By Paving”?

\section{FINDINGS: "what a dynamic, handsome object is a path" 15}

Because my walks always began downtown, along Jasper Avenue, one of the first things I started thinking about was pavement. Can you find desire lines crossing, for example, a concrete plaza? Of course, on concrete, you can't see the paths that are made. But that doesn't mean that habitual paths don't exist. I can imagine that a diagonal across a square plaza might be a popular path, just as diagonal desire lines are often seen cutting across grassy parks. But I'm less certain about whether more exploratory desire lines might be seen, or whether exploratory routes would be taken with any consistency. After all, isn't part of the appeal of a certain route the fact of the path itself? Isn't the visible line part of what makes the route desirable? Would we think to scramble down a steep slope to the river's edge if it weren't evident that someone else had been there before, that someone else had marked the way as worthwhile? Desire lines seem to form concrete (though not paved) evidence that we prefer, quite literally, to follow in each other's footsteps.

When I began my research, one of the questions I had was just what type of desire it is that motivates the formation of desire lines. Is it a desire for haste? A desire for solitude? For adventure? I don't have a scientific answer, but there are some recurring themes that I've found in my wanderings.

I've seen desire lines cutting corners, paths made by feet that know the laws of geometry: the shortest distance between two points is a straight line, and that's the fastest

\footnotetext{
${ }^{13}$ William Lidwell, Kritina Holden, and Jill Butler, Universal Principles of Design, Revised and Updated. ; 115 Ways to Enhance Usability, Influence Perception, Increase Appeal, Make Better Design Decisions, and Teach through Design. (Rockport, 2010), 76.

${ }^{14}$ Don Perkins, posting to Theories of Space

${ }^{15}$ Bachelard, The Poetics of Space, 11.
} 
way to get from the start to the end. I've seen desire lines where the sidewalk ends, where the desire to travel continues, but the sanctioned path does not. Then, the walker makes his own way - finding the door closed, carves out a window. I've seen desire lines that parallel other roads, or split from them - paths that seem unnecessary, but for that fact that they are so travelled. Places where the pedestrian finds something more in the grassy trail, whether it is a softer surface for running, or a sense of exploration. For all of these paths, I've traced that desire with my own words - the paths, photos, and words are online at desirelines.edmontonpipelines.org.

\section{Figure 3: Mapped Desire Lines}

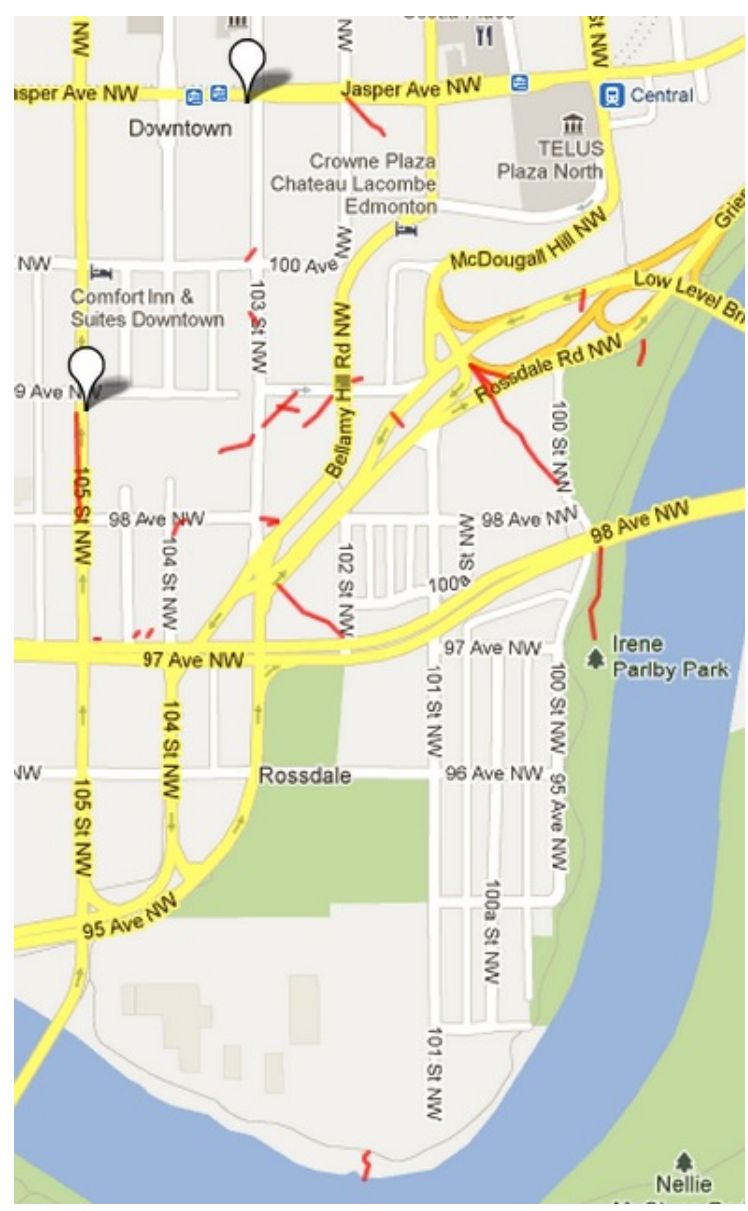

Source: Author illustration.

I've created a map of the desire lines within my study area (see Figure 3), but I don't envision that it will be read as a conventional map might be. I see it less as a tool for navigation, and more of a tool for exploration. The narratives that accompany each line can stand alone, or be read in conjunction with each other. They all follow paths, but the paths 
they follow are different, distinct. Likewise, a reader might follow many paths through my desire lines map - any path they desire, really. They may trace the stories from north to south, methodically, or leap from one to another with an instinctive pattern of choice. Just as a grassy field is open to all lines of desire, I mean my map to be open to all paths of reading. And if, as I hope, my map inspires readers to become walkers too, then the readers will become writers -with their feet, as they retrace old paths and form new ones, and with their minds, which, while following their feet, will doubtless find many more stories than mine.

\section{CONCLUSION: "which is to say, the paths I trace are not the only paths" 16}

On the most basic level, a map is a way of finding something - whether that something is a place, or a path, or a way of seeing; an orientation. When I walk, looking for desire lines, I'm astonished by how much more I notice - not just paths, but whole worlds - fields of wildflowers in abandoned lots, secluded clearings in a dense grove of trees. With that point of view, my map of the city opens up, and I can see more possibilities than just routes from one point to another - I see the spaces in between as well, and I want to know them.

Where will the next line form? Have we drawn our lines dark enough that their histories will last through the winter months, in hibernation as other, snowier lines are traced overtop? Will the lines that I've sketched be erased overtime, or will they remain, more constant even than the paved pathways in a city so often under construction?

In my research, I explored nearly 20 desire lines through multimedia, narrative deep mapping, but the ground I covered is only a fraction of Edmonton's city space, observed over only a fraction of the city's time. While I won't claim that my sample is representative, I will use a similar word: representation. Desire lines are a physical, visible, tangible representation of the way we navigate our city - the way that we take what is built for us, and build upon it. Bachelard wrote: "each one of us, then, should speak of his roads, his crossroads, his roadside benches, each one of us should make a surveyor's map of his lost fields and meadows"17. Desire lines are just that - they are a way of speaking, a way of surveying - a way of making a city our own. They are a place that holds both the past and the present in the space of one footstep, because each footstep that falls follows a hundred earlier feet, while still managing to leave its own impression.

\footnotetext{
${ }^{16}$ Solnit, Wanderlust, 4.

${ }^{17}$ Bachelard, The Poetics of Space, 11.
} 


\section{Bibliography}

Bachelard, Gaston, and M. Jolas. The Poetics of Space. Boston: Beacon, 1994.

Lidwell, William, Kritina Holden, and Jill Butler. Universal Principles of Design, Revised and Updated. ; 115 Ways to Enhance Usability, Influence Perception, Increase Appeal, Make Better Design Decisions, and Teach through Design. Rockport, 2010.

Micallef, Shawn. Stroll: Psychogeographic Walking Tours of Toronto. Toronto: Eye Weekly, 2011.

Perkins, Don. posting to Theories of Space: Mapping Desire Lines in Edmonton "Project Description” 16 May 2012. http://desirelines.edmontonpipelines.org/project-description/

Roelstraete, Dieter. Richard Long: A Line Made by Walking. London: Afterall, 2010.

Solnit, Rebecca. Wanderlust: A History of Walking. New York: Viking, 2000.

Southedmontoncommon.com. http://www.southedmontoncommon.com/about/ 